\title{
Impact of Cultural Trends and Consumer Perception on Brand Reputation in Emerging Clothing Brands of Pakistan
}

\author{
Tabinda Tabassum ${ }^{1}$, Umer Hameed ${ }^{2 *}$ and Sundas Fatima ${ }^{1}$ \\ ${ }^{1}$ University of Management \& Technology, Pakistan \\ ${ }^{2}$ National Textile University, Pakistan
}

*Corresponding author: Umer Hameed, National Textile University, Faisalabad, Pakistan.

\begin{abstract}
The contemporary view of consumers about a brand is based on norms, dogmas, attitudes and practices that constitute lifestyle of people. The process, by which an individual chooses, sorts out and considers a favorable fashion brand to show his life patterns, is the absolute picture of the fashion world. Therefore, brand reputation is an indicator to make a decision to buy new clothes according to cultural norms and values in a society. The fundamental point of this examination is to foresee and to upgrade learning about the idea of brand reputation which has stimulated in Pakistan with social patterns of emerging clothing brands. It aims to investigate whether social ideals and consumer's perception can influence brand reputation. The examination will base on a quantitative report in different scopes of Pakistan. Secondary data is used. Exploratory research approach will be utilized to define issues more precisely. Cultural Trends, Consumer Perception and Brand Reputation are three primary hypotheses of the research. The reason of research is to recognize cultural cues and consumer behavior on brand reputation towards emerging clothing brands of Pakistan. An exploratory linear method design with a convenient strategy is implemented. This examination has used a self-controlled review survey to test size of 200 reporters with an offer of 56 guys with rate of $28.0 \%$ respondents and 144 females with rate of $72.0 \%$ respondents. There will be used non-probability (convenient) sampling design. Reliability Analysis will be used to measure the instrument and researcher will also calculate pilot study. Hypothesis will test through Regression Analysis. The data collected from the survey will be analyzed using the Statistic Package for sociology. The reliability analysis of the adopted instrument of this investigation is conducted on total sample size on $\mathrm{n}=200$ actual respondents. Overall Cronbach's Alpha of questionnaire is 0.87. Researcher used SPSS version 22 for the analysis of collected data. According to results of Regression Analysis Model, Hypothesis 1 and 2 are significant and positive. The study is to ascertain the reason that how much brand reputation/ image is influenced by cultural trends and consumer perception.
\end{abstract}

Keywords: Cultural trends; Consumer perception; Brand reputation; Brands of Pakistan

\section{Introduction}

This research aims to emphasis novice clothing brands of Pakistan. It shows that intensity of brand reputation is directly proportional to cultural trends and consumer perception. The study focuses on consumer's preferences depending upon social norms and values and influence of brand's marketing promotions. The research focuses on launching of new arrival on consumer's buying decisions. During past 6 years, many changes have been taken place in buying behavior of consumers with reference to social and cultural trends [1].

The impact of brands on consumers' purchasing conduct is exceptionally unique and is of awesome significance in Pakistan. Customers keep focus on quality, function ability, pricing and style 
of garments according to social, psychological, religious concerns. Design industry incorporates fashion apparels with young generation in Pakistan and individuals are emphatically connected with fashion and style [2].

In spite of the fact that design industry is in an incipient stage. Pakistan has still possessed the capacity to make a significant image in it. It has a considerable measure of design creators, experts and design managers and merchandizers working in this field. Pakistan has achieved a striking position overall due to its extensive scale textile industry. The apparel industry of Pakistan experienced many changes from raw materials to finishing of garments. A lot of designers, engineers, professional tailors and workers involve gathering up different processing of clothing [3].

There are numerous creators and producers of modern apparel, for example, Maria B, Junaid Jamshed, Sana Safinaz, Gul Ahmed, Mausummery, Wardah, Firdous and Lata Textiles who are producing pieces of clothing and ready to wear articles of clothing. Inside Pakistan they are showcasing through Radio, TV, Print and online media. They are offering at outlets and displays held locally and universally. A great deal of promoting campaigns is presently being helped through Social Media Networking sites [4].

We experience our lives in apparel, we make psychological judgment on someone's dressing, we convey what needs be through attire, and many individuals acquire their livings by making dress. Not all parts of the business are delicate and shining; the methods by which some garments is made are not seen by all. The morals of the fashion business are a key portion of this different business and will be a reliable subject all through this work [5].

To achieve a high level of brands' value, managers and merchandizers worked to create the best image in the mind of consumers. Under the growing importance of brand management, consumers convince more and more to understand the true value of emerging clothing brands. The image of the brand resulted in brand reputation as more consumers get ready to purchase it [6].

\section{Review Literature}

Culture referred to a complex concept and is associated with such activities as profession, literature, architecture, rituals and dress code. Moreover, these forms are associated with urban life and culture is identified with civilization. There is a great difference between elite social class and low social class as culture fluctuates between these two concepts. In other words, the idea of culture gives shape and course to conduct that culture is situated in the region, examples of thoughts, rehearses, establishments, items and artifacts [7].

Cultural difference is the term of clashes among different cultures, as differed to single culture. This phrase cultural difference also refers to distinctive cultures among different zones of land. The phrase Cultural Difference is also used to mean the variety of humans' adaptations or cultures in a specific region, or in the globe as a whole. This difference also stimulates the psychology and philosophy of people having different tastes. Globalization is often said to have a negative effect on the world's cultural diversity. There are many distinctive nations that are differed from each other, and many of these differences are emerged in clothing attitude of people. Similarly, the more obvious cultural differences that exist between people, such as profession, status, dress code and rituals and customs are also important to understand social values. Cultural diversity can be seen as similar to biodiversity [8].

The behavior of a consumer towards a fashion brand refers to the overall estimation of a brand's image, quality of products, style, pricing. Elite class like branded clothes with high quality fabric, good printing results, sophisticated color schemes and delicate designs. Low class prefer low pricing with durability of fabric and glamouring designs. Both of these classes are also conscious for their cultural concepts and social dominancy [9]. Specialists have investigated the effect of brand picture on fulfillment and nature of customer recognition. Speculatively, it can be contended that apparent quality and purchaser satisfaction will directly influence the brand repute [10].

Effective brands alter their image systems as per the reasoning and psychology of individuals as per their groups of friends. Variety in culture is a key factor in triumph or thrashing of brand notoriety [11]. There is a vast scope of situations in which culture has been found to impact purchaser's state of mind. Brand reputation is determined by customers 'or clients' cultural norms and values [12]. It is firmly accepted by scholastic and experts that brand notoriety is noticeably critical. Brands ought to have a positive image in the mind of consumers for the smooth growth of brand repute [13].

On alternate hand, it describes a far-reaching model of five brandrelated procedures: recognizing, encountering, incorporating, flagging and associating with the brand [14]. Frequently, buyers will have a tendency to pick a brand that they express harmony with their point of view. In this specific way every customer at personal level will endeavor to reflect his or her own personality through decision. At the point when a bigger social gathering is held, people have a tendency to localize a specific example of a personal social personality [15]

Brand inclination is viewed as a fix point in consumers' decision leadership, including components of choices. In building up brand preferences, purchasers think about and consider diverse brands by concentrating on their uniqueness. Customers characterize brand inclination as brand managers support their clients and provide services in contrast with other different organizations. Brand makers allude their brands so that a buyer will consider purchasing sooner rather than later [16].

Most investigations on social and cultural diversity are limited to examine the impact of cultural trends by considering consumer 
behavior on brand popularity and brand efficiency. The present research is held to find out a relationship between behaviors and social mentality both inside and crosswise over societies. It aims understanding of purchase intentions by examining uniqueness, self-monitoring, social work endeavors, and full of feelings for extravagance brands among purchasers in Eastern and Western societies [17].

Social contrasts and consumer perception to buy from extravagance brands; uniqueness, quality, perfection and style of garment include. The results of social circle and cultural trends demonstrate that these affects both on buyer conduct and brand notoriety. This examination shows that demands of people are connected to shape the efficiency of brands. Besides, the discoveries of past research and hypothesis show that purchasing behavior of people augment the efficiency of brands crosswise over societies [17].

Consumers build up a strong enthusiastic connection to brands that are connected to central dispositions. The mental approach of customers reflects passionate emotional reactions such as satisfaction and delight. Purchasers frequently react according to their self-dominating and self-representing qualities and objectives because they are guided by their wishes to augment the consistency between their brands and their values. In this way, effective self-presentation as one's status and profession fortify the passionate behavior towards extravagance brands. In this manner, self-expression, which passes on uniqueness, fortifies the enthusiastic prizes from extravagance brands. Brands positively affect full of feelings of state of mind. It is normal that social-circle of people, culture, and self-dominating psyche will positively affect purchasers' perception towards fashion brands [17].

In comparative studies, it is true that efficiency of a product is better evaluated with its competitors. Now a days, consumers have some vital problems because they do not aware of all attributes of a branded product like how to treat with fabric, how to wash , how to iron and what are some specific cautions of different delicate fabrics. Consumers try to focus on certain item traits in a comprehensively way as opposed to a case study. Therefore, both qualities and cautions of products must be accounted in a manner to separate an item from its rivals. In these conditions, brands can possibly assume a wide range of parts in the shopper choice process. The investigation of consumers' perception and opinion making procedure of consumers is a longstanding enthusiasm for advertising and marketing [14].

\section{Materials and Methods}

The information gathering approach was non-probability convenience sampling and test size of 200 respondents was taken. The population for this examination comprises of shopping centers, fashion outlets and colleges of Lahore and Faisalabad. The questionnaire was filled by the purchaser and students in the non-devised conditions on their shopping place and alma mater, and researcher obstruction was insignificant. This particular analysis is cross sectional because of these issues. First issue is that the firm behavior with buyers that has been examined in this study never changed sectional. Secondly available timetable and scarce resources guided this study cross-sectional. It means that population is to be studied for data collection that has been analyzed for results. Since the core objective of this analysis is to understand the brand reputation measuring cultural trends and consumer perception. Therefore, the unit of analysis in buyers is an individual entity as real elements like cultural trends and consumer perception can enhance clothing brands' performance. Researcher collected data from each individual and treated each buyer response as an individual data source. Population means to all inhabitants living in a specific area.

Basically, in this research, all buyers who buy apparels from fashion brands of Faisalabad and Lahore are the elements of the population. Because of some reasons of time and resources it is not possible to collect data from whole population so that's why data obtained from the related sample which is the subpart of population. Sampling in a research is defined as a process of selecting units (e.g., people, and organization) from a population of interest so that by studying the sample researcher may fairly generalize results back to the population from which they were chosen. It comprises some individuals selected from it. After consulting [18] the sample, the research should be able to develop conclusions that generalize respective population. National Brands (2016) analysis shows that Faisalabad and Lahore are the biggest urban areas of Pakistan after Karachi. The region territory of Faisalabad is 5,856 square $\mathrm{km}$ with 12.786 million people; the city populace is 7.14 million. As mentioned in Pakistan (2009-10),"district level employment trends 2009-10" (Karachi-East, Hyderabad, Sialkot and Faisalabad) that in Faisalabad labor force participation rate is 54.5 percent and employment to population ratio is $\mathbf{5 1 . 4}$ percent.

\section{Population Size $=\mathrm{N}=12000$}

There is only single type of sampling technique has been used which is non-probability sampling. In this investigation, researcher has been used non-probability sampling, there is subtype convenience sampling, purposive sampling, quota sampling, this study based on convenience sampling. It is already mentioned above that Lahore is second and Faisalabad is the third biggest city of Pakistan. The data collection from buyers of fashion in different malls of Lahore \& Faisalabad was really a tuff and the most time taking part of this investigation. Researcher has visited 15 shopping malls and 8 universities of Lahore and Faisalabad and collected 200 questionnaires aggregately. The respondent had completed questionnaire and verified the completeness of this questionnaire at the same time.

Sample characteristics are showing from following tables. Table 1 describes the gender share of the employees. Table 2 demonstrates the age classes of buyers of fashion and table No. 3.3 identified the 
percentage of that data which falls in diversified level of education changes from Matric to MA (master's in arts). The following table highlights the buyers of fashion characteristics from whom the data has been gathered.

In this paper, gender is used as control variable and respondents were advised to mention their gender. It is highlighted in Table 1 that male and female share is 56 and 144 respectively. In this investigation 200 correspondents were chosen with percentage of $28.0 \%$ for male correspondents and $72.0 \%$ for

Table 1: Gender of Respondents.

\begin{tabular}{|c|c|c|}
\hline & Frequency & Percent \\
\hline Male & 56 & 28 \\
\hline Female & 144 & 72 \\
\hline Total & 200 & 100 \\
\hline
\end{tabular}

Table 2: Age Distribution of Respondents.

\begin{tabular}{|c|c|c|}
\hline & Frequency & Percent \\
\hline $15-20$ & 4 & 28 \\
\hline $21-25$ & 56 & 37 \\
\hline $26-30$ & 74 & 33 \\
\hline $31-35$ & 66 & 100 \\
\hline
\end{tabular}

Above cited Table 3 demonstrates the third demographic variable which is education. Results show that the literacy level is good in fashion sector of Faisalabad and Lahore because the maximum number of correspondents are M.A $(n=103,51.5 \%)$ and good number of them are B.A $(n=63,31.5 \%)$, a few of them are F.A $(n=$ $30,15.0 \%)$. Only 4 respondents are Matric $(n=6,2.0 \%)$. So, the crux of our discussion is that majority of Faisalabad have very low education level because of national in disturbances, these people are unaware of their rights and firm performance strait as well as the importance of strategic human resource practices and people equity. So, educated respondents were selected to competent evaluation of research. Every item of questionnaire has been measured at five points as Likert scale and answers are ranked as 1=strongly disagree, 2 =disagree, $3=$ neutral, $4=$ agree and $5=$ strongly agree. Akehurst, et al. [19] three most usable demographic variables like female correspondents. There are some issues behind the low participation rate of males because in Pakistan females have more tendency towards fashion as compare to males.

The Table 2 shows the sample formulation with regard to the age which is the second demographic variable of this research. It refers that majority of the respondents are from the age group of $26-30(n=74,67.0 \%)$ years and lowest response rate gets from 1520 years old $(n=4,2.0 \%)$

Table 3: Education of Respondents.

\begin{tabular}{|c|c|c|}
\hline & Frequency & Percent \\
\hline Matric & 4 & 15 \\
\hline FA & 30 & 31.5 \\
\hline BA & 63 & 51.5 \\
\hline MA & 103 & 100 \\
\hline Total & 200 & \\
\hline
\end{tabular}

Table 4: Reliability Analysis.

\begin{tabular}{|c|c|c|}
\hline Variable & No of Items & Cronbach's Alpha \\
\hline CT & 4 & 0.62 \\
\hline CP & 7 & 0.82 \\
\hline BR & 9 & 0.63 \\
\hline
\end{tabular}

gender, age and education for developing people equity has been adopted. To estimate the only dependent variable Brand Reputation (BR) of these items adopted from $[3,20]$ of this measurement include nine items. For the measurement of first independent variable (CT) $[17,21]$ four items have been adopted from this study. To measure the (CP) that is the second independent variable seven items has been also adopted from study. Reliability has been explained by Cronbach, the Cronbach's alpha is known as an internal consistency estimate of reliability of test scores. While the table no. 3.5 describes the reliability analysis of the adopted instrument of this investigation conducted on total sample size on $n=200$ actual respondents. Cronbach alpha values of all three variables are still equal or more than standard value of 0.70 . Therefore, the applied scale of measurement is reliable for its findings. And the overall Cornbach`s alpha of questionnaire is 0.87 (Table 4). 


\section{Results and Discussion}

Researcher used SPSS version 22 for the analysis of collected data. Different statistical tools have been used in this investigation to evaluate below formulated hypothesis. Some tables are used for better description of data making it easy to understand, evaluate and useable. And the crux of this research thesis precisely interprets suggested goals and results following the application in dependent and independent variables. In statistics, standardized coefficients or beta coefficients are the estimates resulting from a regression analysis that have been standardized so that the variances of dependent and independent variables are 1 . Therefore, standardized coefficients refer to how many standard deviations a dependent variable will change, per standard deviation increase in the predictor variable. Standardization of the coefficient is usually done to answer the question of which of the independent variables has a greater effect on the dependent variable in a multiple regression analysis, when the variables are measured in different units of measurements. The coefficients ignore the independent variable's scale of units, which makes comparisons easy. R-squared is a statistical measure of how close the data are to the fitted regression line. It is also known as the coefficient of

Table 5: Descriptive Statistics.

\begin{tabular}{|c|c|c|}
\hline & Mean & Std Deviation \\
\hline Gender & 1.72 & 0.45 \\
\hline Age & 3.01 & 0.833 \\
\hline Education & 3.32 & 0.802 \\
\hline Cultural Trend & 3.7312 & 0.76675 \\
\hline Consumer Perception & 3.5764 & 0.88102 \\
\hline Brand Reputation & 3.6796 & 0.52778 \\
\hline
\end{tabular}

Table 6: Correlation Matrix.

\begin{tabular}{|c|c|c|c|}
\hline & Cultural Trend & Consumer Perception & Brand Reputation \\
\hline Cultural Trend & 1 & $0.570^{* *}$ & 1 \\
\hline Consumer Perception & & $0.664^{* *}$ & 1 \\
\hline Brand Reputation & & \\
\hline
\end{tabular}

\section{Testing of Hypothesis}

\section{H1: Cultural trend is positively related to brand reputation}

Above tables show results of Regression Analysis Model, according to $F$ value of 97.081 ( $p<0.01$ ) hypotheses $H 1$ is significant and positive. It represents the fitness of model. Other measures like R square $=.332$, means that dependent variable 'Brand Reputation' BR explains $33.2 \%$ variation in the independent variable "Cultural Trends" CT. Results also explicate that 'Cultural Trends' CT has positive impact on "Brand Reputation" BR through standardize beta value ( $\mathrm{p}<0.01, \beta=.577)$. It shows that one unit increase in Cultural Trends (CT) will bring 57.7\% increase in "Brand Reputation" (BR). The individual association of CT with BR is ( $p<0.01, t=9.853)$ determination, or the coefficient of multiple determinations for multiple regressions. $0 \%$ indicates that the model explains none of the variability of the response data around its mean.

These discussed values of arithmetic mean and standard deviation regarding different variables are there in Table 5 For Cultural Trends (CT, Mean $=3.7312$, Standard deviation $=0.76675$ ), For Consumer Perception (CP, Mean $=3.5764$, Standard deviation $=0.88102)$ For Brand Reputation (BR, Mean $=3.6796$, Standard deviation $=0.52778$ ). The collected data represents that buyers of shopping malls are agreed with the statement in the instrument regarding all variables because the value of arithmetic mean is very high and indirectly the standard deviation is very low.

\section{Correlation Analysis}

Franzblau elaborated some rules to describe the correlation among variables of the investigation. In above table, it is indicated that positive and high $(\mathrm{p}<.01, \mathrm{r}=0.780)$ correlation is there between Consumer Perception (CP) and Cultural Trends (CT). Positive and moderate $(\mathrm{p}<.01, \mathrm{r}=0.577)$ correlation is there between Brand Reputation (BR) and Cultural Trends (CT). Again, positive and good $(\mathrm{p}<.01, r=0.664)$ correlation found High between Brand Reputation (BR) and Consumer Perception (CP) (Table 6). 
through standardize beta value ( $\mathrm{p}<0.01, \beta=.664)$. It shows that one unit increase in Consumer Perception (CP) will bring $66.4 \%$ increase in Brand Reputation (BR). The individual association of $(\mathrm{CP})$ with $(\mathrm{BR})$ is $(\mathrm{p}<0.01, \mathrm{t}=12.410)$ that is also very considerable.
Based on these results of Regression Analysis, hypothesis H2 has been accepted. Results of this study established that Consumer Perception increase Brand Reputation (Table 8).

Table 7: Results of Linear Regression Analysis of CT on BR.

\begin{tabular}{|c|c|c|c|c|c|c|c|}
\hline & R & R Square & Adjusted R Square & F & T & Beta & Sig. \\
\hline Model Summary & 0.577 & 0.332 & 0.329 & & & \\
\hline ANOVA & & & & 97.081 & & 0 \\
\hline Coefficients & & & & 9.853 & 0.577 & 0 \\
\hline \multicolumn{7}{|c|}{ a. Predictors: (Constant), Cultural Trend } \\
\hline
\end{tabular}

Table 8: Results of Linear Regression Analysis of CP on BR.

\begin{tabular}{|c|c|c|c|c|c|c|c|}
\hline & $\mathbf{R}$ & R Square & Adjusted R Square & $\mathbf{F}$ & $\mathbf{T}$ & Beta & Sig. \\
\hline Model Summary & 0.664 & 0.441 & 0.438 & & & & \\
\hline ANOVA & & & & 154.02 & & & 0 \\
\hline Coefficients & & & & & 12.41 & 0.664 & 0 \\
\hline \multicolumn{8}{|c|}{ a. Predictors: (Constant), Consumer Perception } \\
\hline \multicolumn{8}{|c|}{ b. Dependent Variable: Brand Reputation } \\
\hline
\end{tabular}

\section{Discussion and Conclusion}

This analysis will depict and upgrade learning about the idea of fashion which relies upon brand reputation because of cultural trends and investigation of consumer perception involve. The research is based on a quantitative study in various ranges of Punjab. The research is based on secondary data. Exploratory research methodology will formulate solution of problems in the more definitely and clear up ideas by distinguishing needs of study. Besides, factual study is applied to quantify the nature of research. Cultural Trends, Consumer Perception and Brand Reputation are three primary hypotheses of the research. The reason for research is to recognize cultural values and consumer preferences on brand reputation towards clothing brands of Pakistan. An exploratory linear method design with a convenient strategy is implemented. The result of this research procures explanation for consumers' interests and social values. Moreover, research objectives are defined to extract the impact of cultural trends and consumer perception on brand reputation and to find out the intensity of brand reputation of emerging clothing brands of Pakistan. According to survey research, male and female share is 56 and 144 respectively. In this investigation 200 correspondents were chosen with percentage of $28.0 \%$ for male correspondents and $72.0 \%$ for female correspondents.

There are some issues behind the low participation rate of males because in Pakistan, females have more tendency towards fashion as compare to males. Moreover, majority of respondents are from the age group of $26-30(n=74,67.0 \%)$ years and lowest response rate gets from 15-20 years old $(n=4,2.0 \%)$. In the same manner, maximum number of correspondents are M.A $(n=103,51.5 \%)$ and good number of them are B.A $(n=63,31.5 \%)$, a few of them are F.A $(n=30,15.0 \%)$. Only 4 respondents are Matric $(n=6,2.0 \%)$. Every item of questionnaire has been measured at five points as Likert scale and answers are ranked as $1=$ Strongly Disagree, $2=$ Disagree, $3=$ Neutral, 4=Agree and 5=Strongly Agree. Every link and source have been mentioned above from wherever, items have been adopted. Furthermore, three most usable demographic variables; Gender, Age and Education for developing regions have been adopted. A pilot study is necessary to apply about data set of around 50 employees in order to calibrate the reliability of formulated instrument before the collection of complete data. Aggregately 50 questionnaires rather than sample size were circulated among respondents in the shopping malls of Lahore and Faisalabad which were collected and analyzed later, in order to check the reliability of instrument. The results supported the reliability of applied instrument. The reliability analysis of the adopted instrument of this investigation is conducted on total sample size on $n=200$ actual respondents. Cronbach alpha values of all three variables are still equal or more than standard value of .70. Therefore, the applied scale of measurement is reliable for its findings. Overall Cornbach`s Alpha of questionnaire is .87. Researcher used SPSS version 22 for the analysis of collected data. This investigation has been used different statistical tools to evaluate above formulated hypothesis [22].

Some tables are used, and better description of data makes it easy to understand, evaluate and useable. Similarly, the crux of this research thesis precisely interprets suggested goals and results following the application in Brand Reputation. In the same way, research questions are based on if cultural trends influence brand reputation, and if consumer perception effects brand reputation. Regarding these objectives and questions, results are 
founded that Hypothesis H1 demonstrates that it is approved that first independent variable Cultural Trends (CT) impacts on Brand Reputation (BR). According to results of Regression Analysis Model, F value of 97.081 ( $p<0.01$ ) hypothesis H1 is significant and positive. It represents the Fitness of Model. In the same manner, according to results of Regression Analysis Model, F value 154.020 ( $p<0.01$ ) hypothesis H2 (a) is significant and positive. It represents the fitness of model. In view of these impacts of regression analysis, hypothesis $\mathrm{H} 1$ and hypothesis $\mathrm{H} 2$ has been approved.

\section{Acknowledgement}

None.

\section{Conflict of Interest}

Authors declare no conflict of interest.

\section{References}

1. Becerra PE, Badrinarayanan V (2013) The influence of brand trust and brand identification on brand evangelism. Journal of Product \& Brand Management 22(5/6): 371-383.

2. Khakhan M, Siddiqui KA (2015) Women's Perceptions towards Branded Clothing in Pakistan. Science International 27(5): 4661-4665.

3. Ahmed R, Siddiqui K (2013) Beauty parlor business in Pakistan: Problems \& prospects. Asian Journal of Research in Marketing 2(4): 55

4. Ghani JA (2010) Maria B. Designs (Pvt.) Lt. Asian Journal of Management Cases 7(1): 89-102

5. Lambert M (2014) The Lowest Cost at Any Price: The Impact of Fast Fashion on the Global Fashion Industry.

6. Koca E, Koc F (2016) A Study of Clothing Purchasing Behavior by Gender with Respect to Fashion and Brand Awareness. European Scientific Journal 12(7).

7. Shavitt S, Barnes AJ (2018) Cross-cultural consumer psychology. Consumer psychology 2(1): 70-84.

8. Engelen A, Brettel M (2011) Assessing cross-cultural marketing theory and research. Journal of Business Research 64(5): 516-523.

9. Wu SI, Lo CL (2009) The influence of core-brand attitude and consumer perception on purchase intention towards extended product. Asia Pacific Journal of Marketing and Logistics 21(1): 174-194
10. Ogba IE, Tan (Z 2009) Exploring the impact of brand image on customer loyalty and commitment in China. Journal of Technology Management in China 4(2): 132-144.

11. Roll M (2009) The Impact of Culture on Branding. Branding Strategy Insider.

12. Buil I, de Chernatony L, Hem LE (2009) Brand extension strategies: perceived fit, brand type, and culture influences. European Journal of Marketing 43(11/12): 1300-1324.

13. Veloutsou C, Moutinho L (2009) Brand relationships through brand reputation and brand tribalism. Journal of Business Research 62(3): 314-322.

14. Isik A, Yasar MF (2015) Effects of Brand on Consumer Preferences: A study in Turkmenistan.

15. Cătălin MC, Andreea P (2014) Brands as a mean of consumer selfexpression and desired personal lifestyle. Procedia-Social and Behavioral Sciences 109: 103-107.

16. Jin X, Weber K (2013) Developing and testing a model of exhibition brand preference: The exhibitors' perspective. Tourism Management 38: $94-104$

17. Bian Q Forsythe S (2012) Purchase intention for luxury brands: A cross cultural comparison. Journal of Business Research 65(10): 1443-1451.

18. Turker D, Altuntas C (2014) Sustainable supply chain management in the fast fashion industry: An analysis of corporate reports. European Management Journal 32(5): 837-849.

19. Umbreen U, Rashidi MZ (2012) Influence of Lawn Exhibitions and Brand Outlets on Consumers Buying Behavior. JISR - Management and Social Sciences \& Economics 10(2): 45-60.

20. Cowart KO, Goldsmith RE (2007) The influence of consumer decisionmaking styles on online apparel consumption by college students. International Journal of Consumer Studies 31(6): 639-647.

21. Durmaz Y, Mücahit C, Reyhan O (2003) The impact of cultural factors on the consumer buying behaviors examined through an impirical study. International Journal of Advertising 184

22. Rizvi HA (2002) Pakistan's strategic culture. South Asia in 2020: future strategic balances and alliances: 305 . 